\title{
Numerical modelling of air-cooler using simplified methods
}

\author{
Kamil Śmierciew ${ }^{1}$, Jerzy Gagan ${ }^{1}$, and Dariusz Butrymowicz ${ }^{1, *}$ \\ ${ }^{1}$ Bialystok University of Technology, Wiejska 45C, 15351 Bialystok, Poland
}

\begin{abstract}
The fin-and-tube air coolers have been extensively used in refrigeration systems applied to cold storage chambers. The performance of the heat exchanger affects the efficiency of the systems and makes the study of heat exchanger becomes important. Prediction of the temperature, humidity, as well as velocity distribution in cold storage chamber requires accurate prediction of operation of the finned air cooler. The presence of the air cooler unit is usually taken into account by the investigators, but with very simplified geometry and physics. Results of numerical modelling using the computational fluid dynamics (CFD) software ANSYS FLUENT of fin-and-tube air cooler is presented in the paper. Two different approaches were used: the Dual Cell Model and porous media model.
\end{abstract}

\section{Introduction}

Plate fin-and-tube heat exchangers are widely used in several areas such as HVACR systems. Many experimental studies available in the open literature investigate the air-side heat transfer performance of several types of fins used in finned tube heat exchangers. Among the numerical modelling studies, most of them are focused on performance of heat exchanger, mostly heat transfer coefficient at different geometries or operation conditions [1,2]. Numerical studies on performance of the fin-and-tube heat exchanger under frost condition can also be found $[3,4,5,6]$. However, in some cases, heat exchanger is a part of a large system, where performance of this systems is the most interesting issue. This is also the case of the cold storage chamber. The prediction of the distribution of temperature, humidity, and velocity of air is required in order to ensure the appropriate storage conditions for the stored goods. In such a case an air cooler is a part of the system so that operation of the heat exchanger has to be included in numerical model of the cold storage chamber. However, numerical modelling of operation of the air cooler in a cold storage chamber may be thought as still open problem which is the motivation of the present paper.

The presence of the air cooler unit is usually taken into account in various approaches of modelling of cold storage chamber but with very simplified geometry and physics. The fans forcing the air circulation are mostly represented as infinitely thin plates with assumed pressure jump. The heat exchanger is modelled by means of various approaches. In the work of Chorausia and Goswami [7] the square shaped fins of coils of evaporator in $2 \mathrm{D}$ simulation were taken at constant temperature. Hoang et al. [8] modelled the cooler as a block interacting with the surrounding air flow through the momentum sources computed from the pressure rise in fans and pressure drop due to resistance of the cooler tubes. Delele et al. [9] treated the cooler as porous medium with dominated inertial resistance, calculated by taking into account losses due to wall friction, entrance and exit, and acceleration and deceleration effects. Heat loss to the cooler and the mass source due to condensation/evaporation of water vapour on the cooler was also incorporated in the model.

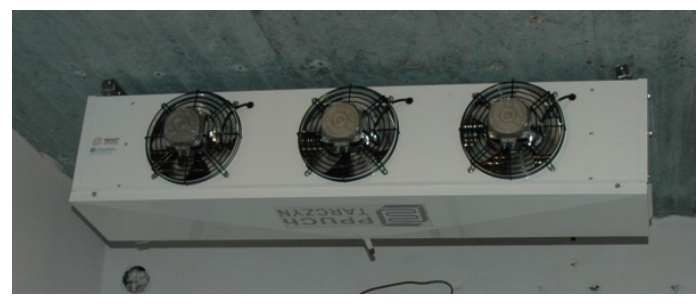

Fig. 1. Front view of the analysed fan-air cooler.

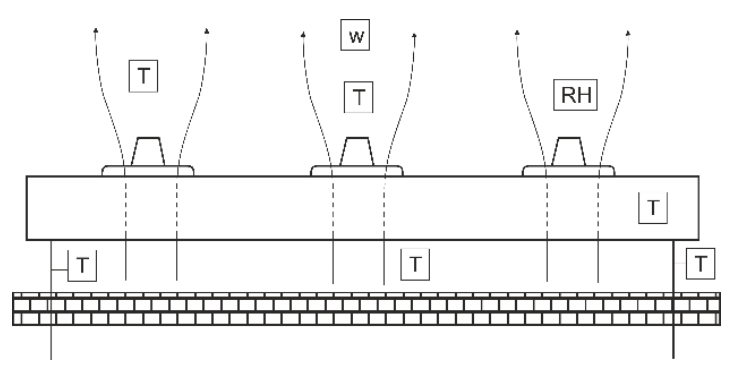

Fig. 2. Location of the measurement sensors.

Overall heat transfer coefficient through the inside surface is calculated from known classical formulae. The amount of transferred heat from air is estimated by using a substitute overall heat transfer coefficient, which value changes within time. Values of the substitute overall heat transfer coefficient may be estimated on the basis of the formulae presented in known publications [1].

\footnotetext{
Corresponding author: d.butrymowicz@.pb.edu.pl
} 
Location of the measurement sensors is shown in Fig. 2. During experiments the temperature of glycol at air cooler inlet and outlet was measured. Temperature of air in front of the air cooler and behind the cooler, air velocity and relative humidity were also measured.

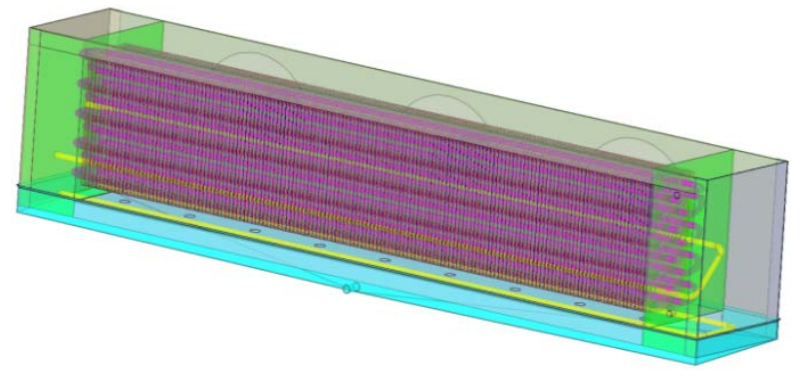

Fig. 3. View on analysed fin-and-tube heat exchanger (aircooler), isometric view at rear side.

\section{Analysis and modelling}

The heat exchanger presented in Fig. 1 and Fig. 3 was taken into consideration. Tested heat exchanger consists of three fans with motors, 18 cooling pipes, 2 heating pipes for defrosting and 150 fins. For numerical simulation some assumption has been made in order to simplify geometry. It was assumed that fans will be represented by plane, and motor will be skipped. Only $1 / 6$ of the heat exchanger is modelled with vertical symmetrical plane. The modelled part contains 25 fins. All of the external walls are assumed to be adiabatic.

The main assumption in modelling was application of porous material as the heat exchanger core. The porous zone is described by source term added to the momentum equation:

$$
\frac{\partial}{\partial t}(\rho \vec{u})+\nabla \cdot(\rho \vec{u} \vec{u})=-\nabla p+\nabla \cdot(\overline{\bar{\tau}})+p \vec{g}+\vec{F}
$$

where

$$
\overline{\bar{\tau}}=\mu\left[\left(\nabla \vec{u}+\nabla \vec{u}^{T}\right)-\frac{2}{3} \nabla \cdot \vec{u} I\right] .
$$

In the source term in the momentum equation, $S_{i}$, the viscosity losses (Darcy's law) - first term on the right hand side of eq. (3) and internal losses - second term on the right hand side of eq. (3) are included:

$$
S_{i}=-\left(\sum_{j=1}^{3} D_{i j} \mu u_{j}+\sum_{j=1}^{3} C_{i j} \frac{1}{2} \rho|u| u_{j}\right)
$$

where: $S_{i}$ is the source term in momentum equation, ( $i=x, y$ or $z$ ), $|u|$ is velocity module and $D$ and $C$ are given matrices. The momentum loss is connect with pressure gradient in porous media. Pressure loss is proportional to velocity of flow. For homogenious porous materials it is:

$$
S_{i}=-\left(\frac{\mu}{\alpha} u_{i}+C_{2} \frac{1}{2} \rho|u| u_{i}\right)
$$

where $\alpha$ is permeability, $C_{2}$ is coefficient of internal resistance per unit thickness, and $D$ and $C$ are diagonal matrices with $1 / \alpha$ and $C_{2}$ respectively, on main diagonal and zeros for rest entries. In laminar flow through porous material pressure drop is directly proportional to velocity and $C_{2}$ can be omit. Ignoring convective and diffusive phenomena, model of flow in porous material is reduced to Darcy's law:

$$
\nabla p=-\frac{\mu}{\alpha} \vec{u}
$$

For higher flow velocity constant $C_{2}$ depends on losses generated by the internal resistance. This coefficient can be considered as loss coefficient in reference to length in flow direction. In the case of a substitute for porous material the permeability term might be omitted and term representing internal resistance only can be used. This leads to:

$$
\nabla p=-\sum_{j=1}^{3} C_{2 i j}\left(\frac{1}{2} \rho u_{j}|u|\right)
$$

or considering all directions $\mathrm{x}, \mathrm{y}, \mathrm{z}$ :

$$
\begin{aligned}
\Delta p_{x} & \approx \sum_{j=1}^{3} C_{2 x j} \Delta n_{x} \frac{1}{2} \rho u_{j}|u| \\
\Delta p_{y} & \approx \sum_{j=1}^{3} C_{2 y j} \Delta n_{y} \frac{1}{2} \rho u_{j}|u| ; \\
\Delta p_{z} & \approx \sum_{j=1}^{3} C_{2 z j} \Delta n_{z} \frac{1}{2} \rho u_{j}|u|
\end{aligned}
$$

The main idea for substitution of the heat exchanger with porous material is to find performance characteristic of porous material as dependence of the pressure drop on flow velocity. In CFD code used in present simulations porous material is described by three terms: porosity $\mathrm{P}$ (scalar), permeability $\alpha$, and coefficient of internal resistance $C_{2}$ (both are vectors). Pressure drop across the heat exchanger was calculated as follows:

$$
\frac{\Delta p}{\Delta l}=\frac{\mu}{\alpha} u+\frac{1}{2} C_{2} u^{2}
$$

Table 1 represents the predicted pressure drop across the tested heat exchanger at different velocities for air. It should be noted that for the investigated heat exchanger there are not any information concerning pressure loss, since it was made for operation at specific conditions in the cold store chamber. According to the data sheets given by the heat exchanger producer the pressure drop for dry air-cooler is $6.7 \mathrm{~Pa}$.

Results were interpolated with second order polynomial with the following function

$$
Y=5.0765 X^{2}+24.0975 X-9.0636,
$$

where $X=u$ i $Y=\Delta p / n$. 
Table 1. Results of numerical calculation.

\begin{tabular}{|c|c|c|}
\hline No. & Velocity $\mathrm{u}$ & $\begin{array}{c}\text { Pressure drop } \\
\Delta \mathrm{p}\end{array}$ \\
\hline & $(\mathrm{m} / \mathrm{s})$ & $(\mathrm{Pa})$ \\
\hline 1 & 0.974 & 1.73 \\
\hline 2 & 2.0 & 5.349 \\
\hline 3 & 3.22 & 10.904 \\
\hline
\end{tabular}

From eq. (8) the coefficients $C_{2}$ and $\alpha$ were calculated: $C_{2}=92.46812$ and $\alpha=6.64799 \cdot 10^{-8}$, therefore, $\frac{1}{\alpha}=1.50421 \cdot 10^{7}$, taking $a_{2}=\left[\begin{array}{l}5.0765 \\ 24.0975 \\ -9.0636\end{array}\right]$ and density $\rho=1.22 \mathrm{~kg} / \mathrm{m}^{3}$ and kinematic viscosity $\mu=1.78 \cdot 10^{-5}$ $\mathrm{Pa} \cdot \mathrm{s}$. Last required parameter is porosity $P$. For modelled domain consisting 25 fins and 25 areas between fins the porosity $P=0.96296$.

For numerical simulation of the heat exchanger with porous material as heat exchanger core the volumetric heat source for heater or heat sink for cooler should be defined. Under real operation conditions coolant is heated by air and coolant temperature is rising. In simulation conditions there is no refrigerant, so the heat taken from air must be reject by heat sink. Based on experimental results, the heat sink per cubic meter was calculated:

$$
\dot{Q}_{\text {sink }}=\frac{\dot{Q}}{V}
$$

where $\mathrm{V}$ is heat exchanger volume $\left[\mathrm{m}^{3}\right], \dot{Q}$ is cooling capacity $[\mathrm{kW}]$.

\section{Results and discussion}

\subsection{Results of numerical simulation of an air- cooler with porous material core}

ANSYS Fluent 16.0 was used in modelling. Fins and spaces between fins in geometrical model of the heat exchanger were replaced by uniform brick with holes for tubes. The coolant flow through the tubes was omitted in calculation, and volumetric heat sink of the specified value was used instead. All external walls were assumed as adiabatic. Simulation were set as steady state. In numerical simulation velocity inlet was set as boundary condition. The average velocity and temperature at heat exchanger outlet were calculated. Also, the colour contour plots of temperature and velocity on various planes across the heat exchanger were generated. Values of inlets and parameters are shown in Table 2. Due to limited volume of the paper the details concerning the solver setup have been skipped. It should be noted that due to technical conditions in the cold storage chamber, the measurements during experiments were taken about $30 \mathrm{~cm}$ before and behind heat exchanger.

Table 2. Experimental and numerical results.

\begin{tabular}{|c|c|c|c|c|}
\hline $\begin{array}{c}\text { Inlet } \\
\text { parameter }\end{array}$ & \multicolumn{2}{|c|}{$\begin{array}{c}\text { Experimental } \\
\text { outlet }\end{array}$} & \multicolumn{2}{c|}{$\begin{array}{c}\text { Numerical } \\
\text { outlet }\end{array}$} \\
\hline $\mathrm{T}_{\text {in }}=275.0 \mathrm{~K}$ & $\mathrm{~T}_{\text {out }}$ & $274.2 \mathrm{~K}$ & $\mathrm{~T}_{\text {out }}$ & $274.3 \mathrm{~K}$ \\
\hline $\mathrm{u}_{\text {in }}=0.94 \mathrm{~m} / \mathrm{s}$ & $\mathrm{u}_{\text {out }}$ & $2.57 \mathrm{~m} / \mathrm{s}$ & $\mathrm{u}_{\text {out }}$ & $2.82 \mathrm{~m} / \mathrm{s}$ \\
\hline
\end{tabular}
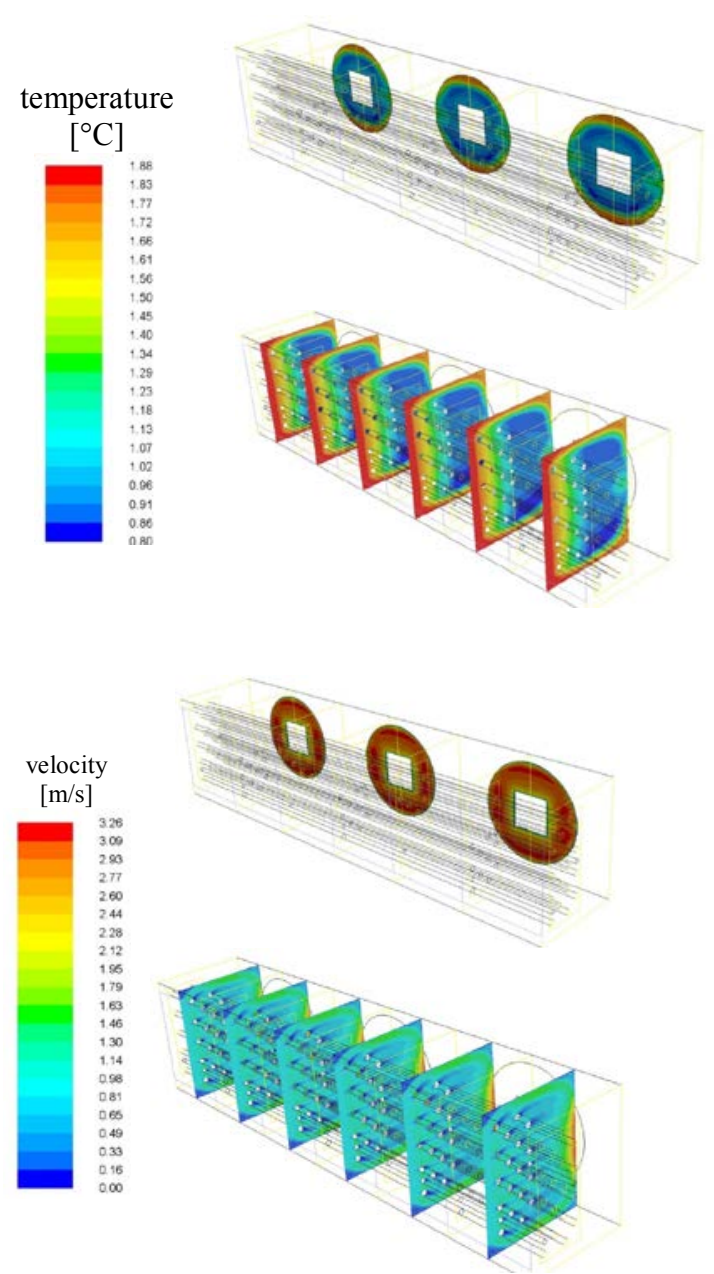

Fig. 4. Temperature field (upper part of the figure) and velocity field (lower part of the figure) at heat exchanger exemplary control plane.

Temperature contour plots at different control planes are presented in Fig. 4. It can be seen that in upper and lower part of the heat exchanger air temperature is higher than inside the core. Also, higher temperature of air can be seen in upper and lower part at the outlet section (see upper part of Fig. 6). This is the result of the existence of large spaces between heat exchanger cover and heat exchanger core (fins surfaces). These empty spaces of 
the air-cooler are free from flow resistance; therefore air easily passes thru these spaces with no particular change of temperature.

Velocity plots at the same control planes are also presented in Fig. 4. Maximum value $u_{\max }=3.26 \mathrm{~m} / \mathrm{s}$ exists at the exit plane. As it was mentioned earlier the mean exit velocity is $u_{\text {out } E X P}=2.57 \mathrm{~m} / \mathrm{s}$ while in CFD simulation the mean value was $u_{\text {out }, C F D}=2.82 \mathrm{~m} / \mathrm{s}$.

Note that the mean velocity taken for comparison not lies exactly at the same plane due to physical limitation of the measurement which was pointed out above. Moreover, outlet velocity resulting from the inlet velocity and flow resistances. Inlet velocity was calculated from the balance equation, and pressure drop due to flow resistance of porous material was found indirectly. It should be noted that there is one physical phenomenon not included in numerical simulations, namely operation of the air-cooler under frost conditions. Growth of frost has additional impact on flow resistance and pressure drop. Nevertheless, it can be concluded in general that modelling of the heat exchanger with porous material predicts outlet temperature and velocity with high accuracy if the pressure drop and heat sink (or source) are known.

\subsection{Results of numerical simulation of an air- cooler with dual cell heat exchanger model}

Modelling of the heat exchanger with dual cell model may be thought as a bit different approach in comparison with modelling using porous material core. Dual cell model assumes that modelled domain contains separate co-located meshes and couples the two flows only through heat transfer at the heat exchanger core. Also, if the heat exchanger has passes or sections, domain for each section/pass should be divided. Figure 5 show the analysed heat exchanger with section division (see also right-hand side of Figure 3). Each of 9 sections has to be divided into two passes. Therefore, entire heat exchanger would have 19 overlapping zones ( 1 brick for air which was set as a primary fluid and 18 smaller bricks for glycol which were set as an auxiliary fluid -2 passes $\times 9$ sections). Note that tubes for glycol are represented by entire core of domain. Every zone of glycol, i.e. inlets and outlets for next pass/section should be thermally coupled. Such complicated domain might be very hard for preprocessing, solver setup and converging and controlling of simulation. It should be noted that literature dealing with application of dual cell heat exchanger model are limited to theoretical construction and limitation of this model provided by ANSYS in ANSYS FLUENT manual [10]. Due to numerous limitations of this model and time-consuming preprocessing procedure in reference to results offered by dual cell model only one section (contains 2 pass) was numerically investigated. Detail schematic of modelled section is shown in Fig. 5.

The procedure for geometry preparation for dual cell model is proposed in ANSYS FLUENT manual [9]. Glycol was the cooling fluid and air was a cooled gas. Operating parameters were found from experimental investigations. Two cases were taken into consideration, before defrost and after defrost.

On the basis of experimental investigation, it was found that air-cooler capacity before defrost was $\dot{Q}_{\exp 1} \cong 370 \mathrm{~W}$ and $\dot{Q}_{\exp 2} \cong 1180 \mathrm{~W}$ after defrost. Since only part of heat exchanger was taken into consideration $(1 / 6 \times 1 / 9=1 / 54)$ the cooling capacity have to be recalculated. Finally, capacities $\dot{Q}_{C F D 1} \cong 7 \mathrm{~W}$ and $\dot{Q}_{C F D 2} \cong 22 \mathrm{~W}$ before and after defrost, respectively were set. In the dual cell heat exchanger model some input parameters have to be known, e.g. desired heat capacity, then experimental data that defines how heat transfer relates to the fluid flow rates have to be set. As a result user can get outlet temperature of fluids for desired heat capacity. Procedure for solver setup are given in ANSYS FLUENT manual [9].
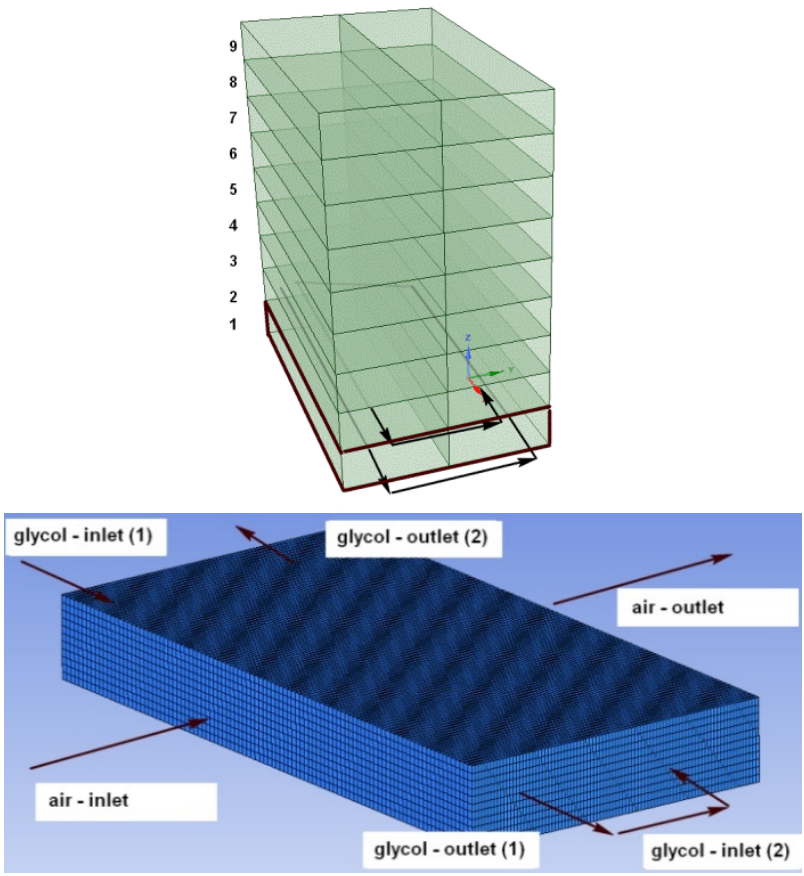

Fig. 5. Numerical domain in original (upper part of the figure) and simplified with boundary description (lower part of the figure).

Boundary conditions were as follows:

- for operation conditions before defrost: $\dot{m}_{\text {in,air }}=$ $0.01619 \mathrm{~kg} / \mathrm{s}, \dot{m}_{\text {in,glycol }}=0.09392 \mathrm{~kg} / \mathrm{s}, \mathrm{T}_{\text {in,air }}=275.3$ $\mathrm{K}, \mathrm{T}_{\text {in, glycol }}=271.1 \mathrm{~K}$;

- for operation conditions after defrost: $\dot{m}_{\text {in,air }}=$ $0.01291 \mathrm{~kg} / \mathrm{s}, \quad \dot{m}_{\text {in,glycol }}=0.09611 \mathrm{~kg} / \mathrm{s}, \mathrm{T}_{\text {in,air }}=275.5$ $\mathrm{K}, \mathrm{T}_{\text {in, glycol }}=270.6 \mathrm{~K}$.

Comparison of numerical and experimental results for operation of air-cooler before and after defrost is shown in Table 3. 
Table 3. Experimental and numerical results for operation before and after defrost.

\begin{tabular}{|c|c|c|}
\hline parameter & Experimental & Numerical \\
\hline & \multicolumn{2}{|c|}{ operation before defrost } \\
\hline thermal capacity Q & $6.895 \mathrm{~W}$ & $6.888 \mathrm{~W}$ \\
\hline $\begin{array}{c}\text { outlet air } \\
\text { temperature tout }\end{array}$ & $274.1 \mathrm{~K}$ & $274.9 \mathrm{~K}$ \\
\hline parameter & Experimental & Numerical \\
\hline operation after defrost \\
\hline thermal capacity Q & $22.01 \mathrm{~W}$ & $22.04 \mathrm{~W}$ \\
\hline $\begin{array}{c}\text { outlet air } \\
\text { temperature tout }\end{array}$ & $274.1 \mathrm{~K}$ & 273.85 \\
\hline
\end{tabular}

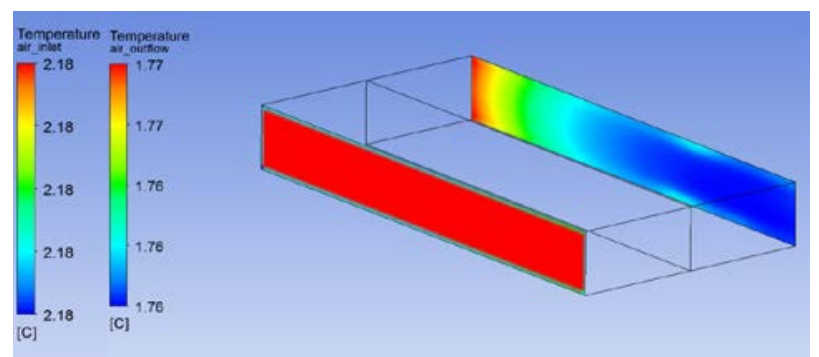

Fig. 6. Air temperature field at inlet and outlet.

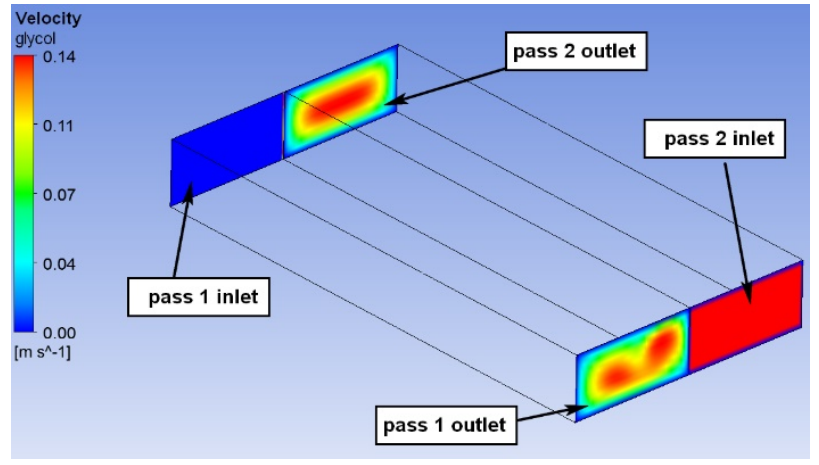

Fig. 7. Glycol velocity field at inlet and outlet.

Temperature field of air for operation conditions before defrost at inlet and outlet plane is resented in Fig. 6. The figure shows that air temperature at the outlet is not uniform. However, the temperature difference between left and right side of the outlet plane is $0.01 \mathrm{~K}$

Velocity field of auxiliary fluid (glycol) at inlets and outlets of both passes is presented in Fig. 7. This figure clearly shows not physical conditions at the transition between 1st pass outlet and 2nd pass inlet. This is an effect of limitation of the discussed dual cell model. First pass outlet velocity is calculated during simulations, while inlet to second pass is defined as boundary conditions (normal to the plane with given value velocity or mass flow rate) which by default is uniform. Both passes are thermally coupled only, therefore information about velocity profile at the second run inlet should be provided by user, e.g. using UDF function.

\section{Conclusions}

Results presented in this paper leads to the following conclusions:
1) Both applied approaches of the heat exchanger modelling have some advantages and disadvantages and limitations.

2) Both approaches require some experimental data necessary for information about heat exchanger performance. Both methods are dedicated to simulation of the heat exchanger as a part of large domain, e.g. storage chamber, cooling room etc. where the heat exchanger is not playing major role, where operation of heat exchanger is not required in details but in general, where the heat exchanger cannot be omitted but it can be simplified.

3) Both approaches predict operation of the heat exchanger with good or acceptance agreement with experiments.

The research results presented in the paper were completed within the statutory activities $\mathrm{S} / \mathrm{WM} / 1 / 2018$ and financed by Ministry of Science and Higher Education and supported by the National Centre of Research and Development, Contract No. PBS1/A8/7/2012.

\section{References}

1. A. Mecke, I. Lee, J.R. Baker jr., M.M. Banaszak Holl, B.G. Orr, Eur. Phys. J. E 14, 7 (2004)

2. M. Ben Rabha, M.F. Boujmil, M. Saadoun, B. Bessaïs, Eur. Phys. J. Appl. Phys. (to be published)

3. H. Bilirgen, S. Dunbar, E.K. Levy, 2013, Numerical modeling of finned heat exchangers, Applied Thermal Engineering 61, pp. 278-288

4. B. Selma, M. Désilets, P. Proulx, 2014, Optimization of an industrial heat exchanger using an open-source CFD code, Applied Thermal Engineering 69, pp. 241-250

5. J. Cui, W.Z. Li, Y. Liu, Y.S. Zhao, 2011a, A new model for predicting performance of fin-and-tube heat exchanger under frost condition, International Journal of Heat and Fluid Flow 32, pp. 249-260.

6. J. Cui, W.Z. Li, Y. Liu, Z.Y. Jiang, 2011b, A new time- and space-dependent model for predicting frost formation, Applied Thermal Engineering 31, pp. 447-457

7. M.K. Chourasia, T.K. Goswami, 2007, Steady state CFD modeling of airflow, heat transfer and moisture loss in a commercial potato cold store, Int. J. Refrig. 30: 672-689.

8. M.L. Hoang, P.Verboven, J. De Baerdemaeker, B.M. Nicolai, 2000, Analysis of the air flow in a cold store by means of computational fluid dynamics, Int. J. Refrig. 23: 127-140.

9. M.A. Delele, A. Schenk, E. Tijskens, H. Ramon, B.M. Nicolai, P. Verboven, 2009a, Optimization of the humidification of cold stores by pressurized water atomizers based on a multiscale CFD model, J. Food Eng. 91,pp. 228-239

10. ANSYS FLUENT 16.0, 2015, Theory Guide. 